Review

\title{
Empty sella prevalence: step by step
}

\author{
Victoria B. Sharavii ${ }^{1}$, Natalia A. Shnayder ${ }^{2,3}$, Lada K. Sharavii ${ }^{4}$, Marina M. Petrova ${ }^{3}$, Regina F. Nasyrova ${ }^{2}$ \\ ${ }^{1}$ I. M. Sechenov First Moscow State Medical University (Sechenov University), Moscow, Russia \\ 2 V.M. Bekhterev National Research Medical Center for Psychiatry and Neurology, St. Petersburg, Russia \\ ${ }^{3}$ V.F. Voyno-Yasenetsky Krasnoyarsk State Medical University, Krasnoyarsk, Russia \\ ${ }^{4}$ Public healthcare institution of Republic of Tuva Republican children's hospital, Kyzyl, Russia
}

Received 21 February 2021, Revised 26 April 2021, Accepted 27 April 2021

(C) 2021, Sharavii V.B., Shnayder N.A., Sharavii L.K., Petrova M.M., Nasyrova R.F.

(C) 2021, Russian Open Medical Journal

Abstract: An empty sella (ES), also known as an empty sella turcica (empty pituitary fossa) is defined as an intrasellar herniation of subarachnoid space within the sella which leads to flattening of the pituitary gland towards the posteroinferior wall.

Purpose - to analyze studies of ES prevalence in the world.

Methods - We carried out a systematic search in both Russian and English databases (E-library, PubMed, GoogleScholar, OxfordPress, ClinicalKeys) using keywords "empty sella", "empty sella turcica", "empty pituitary fossa", "prevalence" and their combinations. The period of search: 2000-2020. It is also worth noting that earlier publications of historical interest were included in the review.

Results - We have analyzed 23 studies. They can be roughly devided into two groups: the first group - screening studies of ES, the second group - targeted studies of ES.

Keywords: empty sella, empty sella turcica, empty pituitary fossa, prevalence, frequency.

Cite as Sharavii VB, Shnayder NA, Sharavii LK, Petrova MM, Nasyrova RF. Empty sella prevalence: step by step. Russian Open Medical Journal 2021; 10: e0206.

Correspondence to Natalia A. Shnayder. Address: V.M. Bekhterev National Medical Research Center for Psychiatry and Neurology, 3 Bekhtereva St., SaintPetersburg 192019, Russia. Phone: +79135354777. E-mail: naschnaider@yandex.ru.

\section{Introduction}

An empty sella (ES), also known as an empty sella turcica (empty pituitary fossa) is defined as an intrasellar herniation of subarachnoid space within the sella which leads to flattening of the pituitary gland towards the posteroinferior wall $[1,2]$.

ES can be divided into partial and complete (Figure 1) on the basis of the degree to which cerebrospinal fluid (CSF) occupied the intrasellar space and flattened the superior surface of the pituitary gland. Partial ES occurs when sella turcica (ST) is partially filled with CSF up to a level of $<50 \%$. Complete ES manifests when ST is completely filled with CSF up to a level of $>50 \%$ [3].

Depending on its etiology, ES can be also classified as primary and secondary. In the case of primary ES (PES), the etiology of the pituitary gland atrophy is not clear. Several etiopathogenetic hypotheses have been proposed. Congenital anomalies in incomplete formation of the diaphragm of ST are being discussed as a possible mechanism [4]. Secondary ES (SES) may be caused by pituitary adenomas undergoing spontaneous necrosis (ischemia or hemorrhage), radiotherapy, drugs, previous surgery, infective, autoimmune, and traumatic causes $[5,6]$.

There is still some debate over whether who first introduced the term 'empty sella', W. Bush or H. L. Sheehan and V. K. Summers. Both of them used this term in the 1950s (1951 and 1949, respectively) while describing pituitary necrosis in postpartum women. Particularly W. Busch, in 1951, performed a large study of 788 human cadavers during autopsy examination of the sella turcica and observed in 40 of 788 , predominantly women, a sella turcica with an incomplete diaphragma sellae, where the pituitary gland was not absent but flattened in a way that it formed a thin layer of tissue in the periphery [7-12].

Furthermore, W. Busch offered three main types of the diaphragma sellae. According to him, type I-A is characterized by diaphragma sellae forming the complete covering of the hypophyseal stalk. Type I-B presents a slight funnel-shaped impression in the fully formed diaphragma sellae. Type II-A exhibits incompletely closed diaphragma sellae with a $3 \mathrm{~mm}$ or less opening around the hypophyseal stalk. Type II-B demonstrates a slight funnel-shaped indentation towards the middle. Finally, in type III a diaphragma sellae is a peripheral ring of tissue $2 \mathrm{~mm}$ or less with: A - hypophysis freely exposed but covered with an arachnoid membrane without depression of the tissue, B eccentric compression of the pituitary gland, C - the pituitary gland flattened to the bottom [9].

The next era of research into this phenomenon started in 1957 when new methods of diagnosis were introduced. Therefore, due to the advent of X-RAY and craniography, in $1957 \mathrm{G}$. Robertson showed intrasellar air on pneumoencephalograms, and in $1958 \mathrm{E}$. P. Engels demonstrated the presence of pituitary gland during cervical myelography with ethyl iodophenylundecylate [9]. 


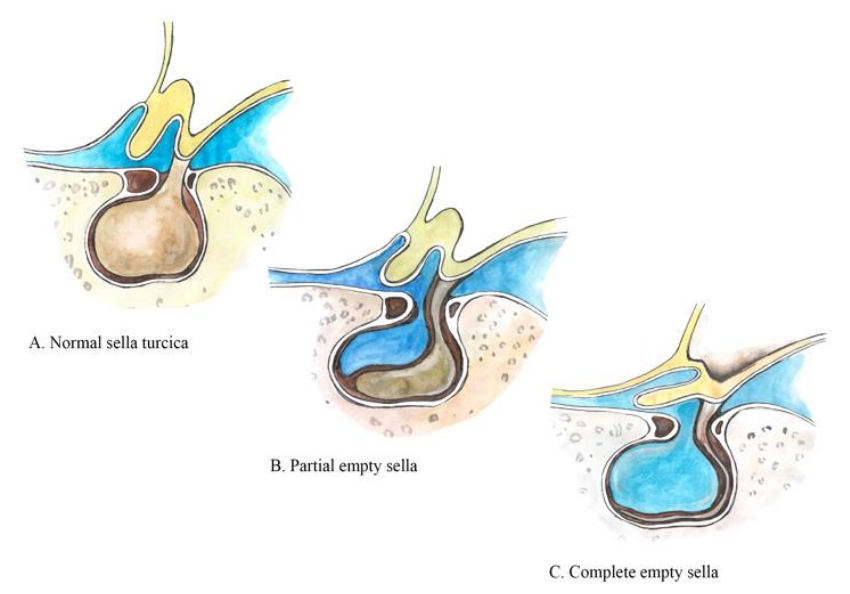

Figure 1. Development of empty sella.
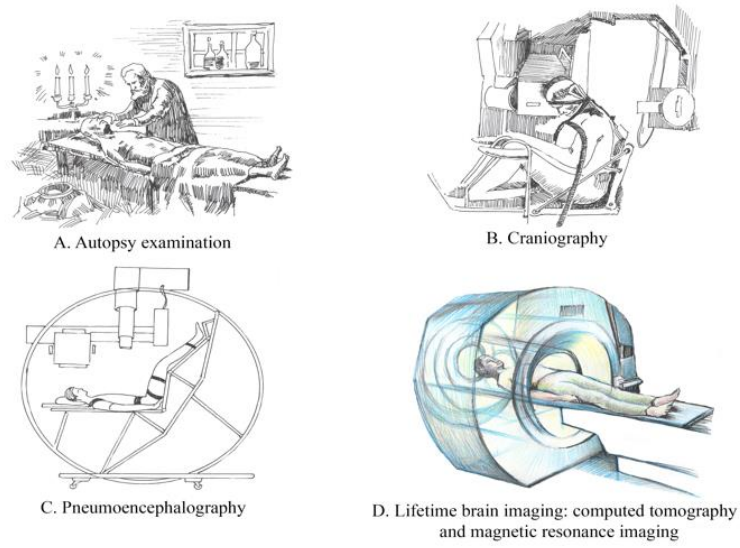

Figure 2. Evolution of brain examination methods of empty sella.

Over the years, the term was increasingly recognized by radiologists observing a similar phenomenon in computed tomograms (CTs) and magnetic resonance imaging scans (MRIs) of the brain in day-to-day practice $[3,8,13]$. With an ever-increasing number of patients undergoing CT and MRI, the reported prevalence of ES is set to rise proportionately [1]. Nowadays, ES is mostly considered as a common but incidental finding in brain imaging owing to the fact that SES is rare and there are no proper clinical presentations associated with this condition [5]. Coronal scans of MRI are reported to be more sensitive than computed tomography (CT) for the diagnosis of ES [3], as it provides more soft tissue details [14].

Therefore, the prevalence of ES has strongly correlated with the advent and improvement of new methods of brain imaging (Figure 2) and the implementation of these diagnosis methods into routine clinical practice.

\section{Material and Methods}

We carried out a systematic search in both Russian and English databases (E-library, PubMed, GoogleScholar, OxfordPress, ClinicalKeys) using keywords 'empty sella', 'empty sella turcica', 'empty pituitary fossa', 'prevalence' and their combinations. The period of search: $2000-2020$. It is also worth noting that earlier publications of historical interest were included in the review.

\section{Results}

We have analyzed 23 studies (Table 1) that were conducted in the USA (2), India (3), Italy (6), China (2), Argentina (2), Saudi Arabia (1), Colombia (1), Iran (1), Russia (2), Turkey (2), Egypt (1). In total, the study included 46962 patients.

By design, the studies can be roughly divided into two groups. The first group consisted of screening studies (Table 1) that examined the incidence of ES among all patients who underwent brain imaging without regard for the presence of clinical manifestations of ES. The second group incorporated targeted studies (Table 2) that included patients with clinical manifestations characteristic of ES.

\section{Screening studies of ES}

Colao A. et al. (2013) performed a retrospective study held in three Italian tertiary health care centers. PES was found in 94 patients out of the cohort of 1484 individuals (6.33\%), with 39 male and 55 female patients with mean age $50.2 \pm 0.9$ years, which proves once again a higher prevalence of ES in the female population [15].

The prevalence of ES in India was investigated in the large retrospective study including a total of 12414 patients who underwent MRI of the brain for various indications reported by Debnath C.J. et al. (2016) [1]. The study period was ranging from 01 April 2006 to 31 March 2015. ES was found in 241 (1.94\%) patients;

$110(45.6 \%)$ patients both male and female were $30-50$ years old. Males $(57.7 \%)$ were predominant in the list of patients with ES despite the fact that in the world literature there is a four-fold female predominance.

Riaño H.D.C. et al. (2018) documented ES in 140 out of 630 patients $(24 \%)$ in a Colombian population in a descriptive observational cross-sectional study from November 2016 to April 2017. Of these, they documented a peak increase in female gender in the age group 80-90 years and in male gender in the age group $60-90$ years. The prevalence of ES was higher in females [16].

Shuyan L. et al. (2019) conducted an ongoing population-based neuroimaging study initiated in March 2013 in Taizhou City, China. Overall, the study included a total of 562 individuals who participated and completed all procedures from March 2013 to January 2015, among these there were 303 women (53.91\%) and 259 men $(46.09 \%)$ with mean age $59.25 \pm 2.72$ years. ES was evaluated in 11 patients out of 562 participants (1.96\%). There is no information about sex and age prevalence in the group of patients with ES [17].

In the retrospective study conducted by Nwafor N.N. et al. (2019) over a period of three years between May 2016 and 2019 at a private radiodiagnostic center in Nigeria, the prevalence of ES was investigated. However, the authors did not mention the total number of cases that were included in the study and the total number of patients with the presumptive diagnosis of ES. Nevertheless, it is worth mentioning that a total of 8 females between the ages of 34 and 56 years who presented with various chronic clinical symptoms had an imaging finding of ES on MRI [5].

Ekhzaimy A.A. et al. (2020) carried out a ten-year retrospective analysis of PES cases in the period 2007 to 2017, from a single tertiary care referral hospital in Saudi Arabia. According to their results, 765 out of 26218 patients $(2.92 \%)$ who underwent MRI in this period were diagnosed to have PES. Among these, PES 
preponderance was noted with 607 females and 158 males with a male:female ratio of 1:3.8 suggesting female predominance by almost four times. However, a peak increase in both male and female patients was documented in the age group older than 50 years. It is interesting to note that $79 \%$ of the cases were diagnosed as incidental findings and only $20 \%$ were seen by endocrinologists due to the presence of clinical presentation [18].

Zademir M. et al. (2020) held a retrospective descriptiveanalytic study which included 1856 patients referred to Imam Ali Hospital in Iran for MRI of the brain during the first 6 months from 21 March 2018 to 23 September 2018. According to their results, the prevalence of ES was $8.2 \%$ with a mean age of $37.02 \pm 12.51$ years, among them $66.4 \%$ of the patients were female. Moreover, the prevalence of PES was $78.9 \% .71 .7 \%$ of patients had partial ES [19].

Auer M.K. et al (2018) [3] identified 2523 publications by using the search term 'empty sella'; 1282 of these were published between 1995 and 2016. Applying further exclusion criteria yielded 120 remaining studies of PES. Only four of these studies dealt with PES as an incidental finding and had used appropriate endocrinological and radiological diagnostic evaluation methods. According to current data from India, ES without any detectable cause is an incidental finding in about $2 \%$ of all brain MRI scans. The prevalence of PES, i.e. ES without any discernible cause, is not precisely known; estimates range from $2 \%$ to $20 \%$

\section{Targeted studies of ES}

ES and idiopathic intracranial hypertension without hormonal disturbances. The worldwide incidence of idiopathic intracranial hypertension $(\mathrm{IIH})$ is around $0.5-2$ per 100000 people per year in the general population [20]. $\mathrm{IIH}$ is predominantly seen in obese women of childbearing age and less common in men $[20,21]$.

Although the etiology of IIH is still unclear, it can be associated with ES in some cases. We found three targeted studies of ES prevalence in patients with IIH without hormonal disturbances [2, 22 , 23]. Prevalence of ES varied from $2.5 \%$ [22] to $14 \%$ [2].

Moreover, several IIH associated with ES can be quite high. Therefore, it can become an indication for neurosurgical treatment.

Thus, Fouad W. (2011) analyzed 20 clinical cases of patients with IIH associated with ES. All patients underwent different surgical procedures including extradural transsphenoidal packing of the sella, subfrontal craniotomy with intradural repair of the anterior cranial fossa, application of thecoperitoneal shunt, extradural transsphenoidal packing of the sella turcica followed by reconstruction of the sellar floor, the reconstruction of the sellar floor. It should be noted that $60 \%$ of patients had PES and $40 \%$ had SES [23].

Furthermore, we found one targeted study in which authors showed an association between ES and increased intracranial pressure in patients with traumatic brain injury [24].

Table 1. Screening studies of empty sella

\begin{tabular}{|c|c|c|c|c|c|}
\hline \multirow{2}{*}{ Reference } & \multirow{2}{*}{ Country } & \multirow{2}{*}{ Patients (n) } & \multicolumn{2}{|c|}{ Gender } & \multirow{2}{*}{ Prevalence (\%) } \\
\hline & & & Male (n) & Female $(n)$ & \\
\hline Colao A et al. (2013) [15] & Italy & 1484 & no label & no label & $6.33 \%$ \\
\hline Debnath CJ et al. (2016) [1] & India & 12414 & 9982 & 2516 & $1.94 \%$ \\
\hline Riaño HDC et al. (2018) [16] & Colombia & 630 & no label & no label & $24 \%$ \\
\hline Shuyuan L et al. (2019) [17] & China & 562 & 259 & 303 & $1.96 \%$ \\
\hline Ekhzaimy AA et al. (2020) [18] & Saudi Arabia & 26218 & 158 & 607 & $2.92 \%$ \\
\hline Zademir M et al. (2020) [19] & Iran & 1856 & no label & no label & $8.2 \%$ \\
\hline
\end{tabular}

Table 2. Targeted studies of empty sella

\begin{tabular}{|c|c|c|c|c|c|}
\hline \multirow{2}{*}{ Reference } & \multirow{2}{*}{ Country } & \multirow{2}{*}{ Patients ( $n$ ) } & \multicolumn{2}{|c|}{ Gender } & \multirow{2}{*}{ Prevalence (\%) } \\
\hline & & & Male $(n)$ & Female $(n)$ & \\
\hline \multicolumn{6}{|c|}{ Idiopathic intracranial hypertension without hormonal disturbances } \\
\hline Yuh WTC et al. (2000) [22] & USA & 100 & 45 & 55 & Total ES - $2.5 \%$ \\
\hline Fouad W (2001) [23] & Egypt & 20 & 5 & 15 & PES - $60 \%$ SES - $40 \%$ \\
\hline Saindane AM et al. (2013) [2] & USA & 657 & no label & no label & Total ES - $14 \%$ \\
\hline \multicolumn{6}{|c|}{ Isolated hyperprolactinemia } \\
\hline Ghatnatti V et al. (2012) [30] & India & 34 & 9 & 25 & PES - $71 \%$ SES - $29 \%$ \\
\hline Nad' YG (2017) [29] & Russia & 1759 & no label & no label & Total ES $-2.5 \%$ \\
\hline \multicolumn{6}{|c|}{ Symptomatic hormonal disturbances } \\
\hline Dedov II et al. (2001) [31] & Russia & 71 & 46 & 25 & Total ES - $33.8 \%$ \\
\hline Cannavo S et al. (2002) [35] & Italy & 43 & 10 & 33 & PES $-51 \%$ SES $-49 \%$ \\
\hline De Marinis L et al. (2005) [4] & Italy & 213 & 42 & 171 & Complete PES - $65 \%$ Partial PES - $35 \%$ \\
\hline Guitelman $\mathrm{M}$ et al. [36] & Argentina & 175 & 25 & 150 & Complete PES - $69 \%$ Partial PES - $31 \%$ \\
\hline Reddy Pa et al. (2013) [34] & India & 16 & 5 & 11 & Total ES - $100 \%$ \\
\hline Zuhur SS et al. (2014) [37] & Turkey & 81 & 11 & 70 & Complete PES - $42 \%$ Partial PES - $58 \%$ \\
\hline Liu W et al. (2015) [32] & China & 152 & no label & no label & Total ES - $20.3 \%$ \\
\hline Lubrano C et al. (2015) [33] & Italy & 184 & 37 & 147 & Total ES - $71.2 \%$ \\
\hline \multicolumn{6}{|c|}{ Cushing's disease } \\
\hline Manavela MP et al. (2001) [38] & Argentina & 68 & 55 & 13 & Total ES - $16.1 \%$ \\
\hline \multicolumn{6}{|c|}{ Autoimmune abnormalities of the pituitary gland } \\
\hline Lupi I et al. (2011) [39] & Italy & 101 & 24 & 77 & PES $-84 \%$ SES - $16 \%$ \\
\hline \multicolumn{6}{|c|}{ Sheehan syndrome } \\
\hline Özkan Y et al. (2005) [40] & Turkey & 20 & 0 & 20 & Complete ES - $55 \%$ Partial ES - $45 \%$ \\
\hline \multicolumn{6}{|c|}{ Traumatic brain injury outcomes } \\
\hline Fama F et al. (2019) [24] & Italy & 104 & 62 & 42 & Total ES - $36.54 \%$ \\
\hline
\end{tabular}

ES, empty sella; PES, primary empty sella; $S E S$, secondary empty sella. 
ES and isolated hyperprolactinemia. Concern for the problem of isolated hyperprolactinemia (IHPE) dates back to the 70-the 80s of the 20th century.

Thus, in 1983 Gharib H. [25] performed a study that involved 11 women with concurrent IHPE and PES. All patients underwent radiological investigations including sellar polytomography, CT of the brain, bilateral carotid angiography, and pneumoencephalography. Moreover, histological and immunological studies of the pituitary gland were performed in some of the patients, and no abnormalities were found [25].

The cause of IHPE associated with ES is still unknown. However, it could be accompanied by galactorrhea and amenorrhea, which is clinically important for women of childbearing age and adolescents of both genders.

In subsequent years, concern for this phenomenon has not waned. Due to the practical application of brain MRI into clinical practice, the hypothesis that IHPE can be an endocrinological abnormality in the population of patients with ES was confirmed.

In addition, in most cases, IHPE is often not accompanied by histological changes of the pituitary gland itself. Thus, we found 3 case-studies that described this phenomenon. Twin and Brophy (2012) described a 46-year-old female patient with isolated galactorrhea and elevated prolactin level in the blood. Viral and inflammatory brain diseases were excluded and a brain MRI was performed. IHPE was associated with ES [26]. Although the association of macroprolactinemia and ES is rare, Ach Taieb et al. (2017) reported a case of a 47-year-old female patient with bilateral galactorrhea and spaniomenorrhea since the age of 37 years. Brain MRI showed ES. Therefore, according to the authors, isolated macroprolactinemia can be in strong association with ES [27]. Moreover, Blevins Jr. L. (2018) described a case of a female patient with the evaluation of ES and IHPE. She had a prolactinoma due to which SES developed [28].

Overall, despite its clinical significance, the number of targeted studies is small. We found two targeted studies, according to which prevalence of ES with IHPE varied from 2.5\% [29] to $20.8 \%$ [30].

ES and symptomatic hormonal disturbances. The greatest number of targeted studies of ES involved patients with symptomatic hormonal disturbances including hyperpituitarism, hypopituitarism, hyperprolactinemia, hypothyroidism, gonadotropin, $\mathrm{GH}$, and adrenal deficiency. In most studies patients were referred to do brain MRI in endocrinology clinics. Patients with ES had variable clinical conditions ranging from mild endocrine disturbances to severe intracranial hypertension and rhinorrhea.

In total, we have analyzed eight studies of ES associated with symptomatic hormonal disturbances. One study was carried out in Russia [31] and seven studies were held overseas [4, 32-37]. Overall incidence of ES varied from $20.3 \%$ [32] to $100 \%$ [34]. Mean prevalence was $56,33 \%$ [31-34]. It is important to note that in most cases patients had PES, the prevalence of which varied from $51 \%$ [35] to $69 \%$ [36]. On the contrary, the prevalence of SES was $49 \%[35]$.

\section{Discussion}

Our systematic analysis of screening and targeted studies of pathological conditions associated with empty sella syndrome indicates that the increase in the prevalence of PES in the population is due to the introduction of new methods of lifetime brain imaging.

According to the results of screening studies of ES, the mean prevalence of PES in the population was $7.56 \%$.

Meanwhile, according to the results of targeted studies of ES, the prevalence of PES with clinical manifestations vary depending on associated pathological conditions: $1 \mathrm{IH}$ - from $2.5 \%$ to $60 \%$, IHPE - from $2.5 \%$ to $71 \%$, symptomatic hormonal disturbances - up to $100 \%$. Moreover, we found several studies of PES prevalence in patients with Cushing's disease $-16.1 \%$ [38], with autoimmune abnormalities of the pituitary gland - 84\% [39], with Sheehan syndrome [40]. It is worth noting that we found studies of PES associated with rare and unusual presentations such as sinus bradycardia, refractory hypoglycemia, and seizures [41, 42].

Therefore, both asymptomatic and symptomatic cases of PES need particular attention from neurologists, endocrinologists, and radiologists. A finding of PES using brain imaging performed for various reasons such as headaches, dizziness, oligomenorrhea, galactorrhea, CFS rhinorrhea, visual abnormalities, neurological symptoms require a multidisciplinary approach for early detection of pathological conditions associated with PES because in some cases conservative treatment is not efficient enough. On this account, neurosurgical treatment has to be performed [23].

\section{Conclusion}

$E S$, especially $P E S$, is one of the topical problems of modern neuroendocrinology. Implementation of new methods of lifetime brain imaging, such as CT and functional MRI, into day-to-day practice, broaden the understanding of this underinvestigated disease.

It should be acknowledged that the real prevalence of ES, including PES and SES, is significantly higher than previously thought. Due to the fact that currently published studies of ES predominantly include a small number of patients, our systematic analysis shows that large multicenter screening and targeted studies of PES and SES are required to be conducted in various racial and ethnic groups of patients and in association with various clinical conditions. Different designs of studies and sampling variability by race, ethnicity, and gender of patients are a significant limitation for systematic analysis and make it more challenging to conduct.

\section{Conflict of interest}

We declare that we have no conflict of interest.

\section{Acknowledgements}

We acknowledge Baylak Borbakovich Sharavii who has contributed to the study by preparing all pictures in the article.

\section{References}

1. Debnath J, Ravikumar R, Sharma V, Senger KPS, Maurya V, Singh G, et al. 'Empty sella' on routine MRI studies: An incidental finding or otherwise? Med J Armed Forces India 2016; 72(1): 33-37. http://dx.doi.org/10.1016/j.mjafi.2015.11.012.

2. Saindane $A M$, Lim PP, Aiken A, Chen Z, Hudgins PA. Factors determining the clinical significance of an "empty" sella turcica. AJR Am J Roentgenol 2013; 200(5): 1125-1131. http://doi.org/10.2214/AJR.12.9013 
3. Auer MK, Stieg MR, Crispin A, Sievers C, Stalla GK, Kopczak A. Primary empty sella syndrome and the prevalence of hormonal dysregulation. Dtsch Arztebl Int 2018; 115(7): 99-105. http://doi.org/10.3238/arztebl.2018.0099.

4. De Marinis L, Bonadonna S, Bianchi A, Maira G, Giustina A. Primary empty sella. J Clin Endocrinol Metab 2005; 90(9): 5471-5477. http://doi.org/10.1210/jc.2005-0288.

5. Nwafor NN, Akhigbe AO. Diverse clinical manifestation of empty sella syndrome: An imaging based study. Saudi J Health Sci 2019; 8(3): 172175. http://doi.org/10.4103/sjhs.sjhs 12219.

6. Gouliamos AD, Athanassopoulou AK, Souvatzoglou AM, Kalovidouris AE, Vlahos LI, Papavasiliou CG. Magnetic Resonance Imaging in Empty Sella Phenomena. Journal of Neuroimaging 1993; 3(3): 173-177. http://doi.org/10.1111/jon199333173.

7. Chiloiro S, Giampietro A, Bianchi A, Tartaglione T, Capobianco A, Anile $C$, et al. DIAGNOSIS OF ENDOCRINE DISEASE: Primary empty sella: a comprehensive review. Eur J Endocrinol 2017; 177(6): R275-R285. http://doi.org/10.1530/eje-17-0505.

8. Manavela MP, Goodall CM, Katz SB, Moncet D, Bruno OD. The association of Cushing's desease and primary empty sella turcica. Pituitary 2001; 4(3): 145-151. http://doi.org/10.1023/a:1015310806063.

9. Kaufman B. The 'empty' sella turcica - a manifestation of the intrasellar subarachnoid space. Radiology 1968; 90(5): 931-941. http://doi.org/10.1148/90.5.931.

10. Atherton WW, Kettner NW. The empty sella. J Manipulative Physiol Ther 1999; 22(7): 478-482. http://doi.org/10.1016/s01614754(99)70037-0.

11. Sheehan HL, Summers VK. The syndrome of hypopituitarism. Q J Med 1949; 18(72): 319-378. https://pubmed.ncbi.nlm.nih.gov/15398358.

12. Busch W. Morphology of sella turcica and its relation to the pituitary gland. Virchows Arch Pathol Anat Physiol Klin Med 1951; 320(5): 437458. German http://doi.org/10.1007/BF00957474.

13. Lubrano C, Tenuta M, Costantini D, Specchia P, Barbaro G, Basciani S, et al. Severe growth hormone deficiency and empty sella in obesity: a cross-sectional study. Endocrine 2015; 49(2): 503-511. http://doi.org/10.1007/s12020-015-0530-0.

14. Liu W, Zhou H, Neidert MC, Schmid C, Bernays RL, Ni M, et al. Growth hormone secreting pituitary microadenomas and empty sella - An under-recognized association? Clin Neurol Neurosurg 2014; 126: 1823. http://doi.org/10.1016/j.clineuro.2014.08.012.

15. Colao A, Cotta OR, Ferone D, Torre ML, Ferraù F, Di Somma C, et al. Role of pituitary dysfunction on cardiovascular risk in primary empty sella patients. Clin Endocrinol (Oxf) 2013; 79(2): 211-216. https://doi.org/10.1111/cen.12122.

16. Riaño HDC, Pedroza LVR, Cabana LMP, León JST. Empty Sella Syndrome Prevalence in a Colombian Population and Its Relation with Age, Sex and Number of Pregnancies. Rev Colomb Radiol 2018; 29(2): 49084914.

https://www.webcir.org/revistavirtual/articulos/2018/3 agosto/col/sil la eng.pdf.

17. Li S, Fang $F$, Cui $M$, Jiang $Y$, Wang $Y$, Kong $X$, et al. Incidental findings on brain MRI among Chinese at the age of 55-65 years: the Taizhou Imaging Study. Sci Rep 2019; 9(1): 464-471. http://doi.org/10.1038/s41598-018-36893-0.

18. Ekhzaimy AA, Mujammami M, Tharkar S, Alansary MA, Al Otaibi D. Clinical presentation, evaluation and case management of primary empty sella syndrome: a retrospective analysis of 10-year single-center patient data. BMC Endocr Disord 2020; 20(1): 142. https://doi.org/10.1186/s12902-020-00621-5.

19. Zademir M, Sargolzaie N, Nourolah A. Prevalence of empty sella syndrome. Tehran Univ Med J 2020; 78(4): 248-254. Persian. http://tumj.tums.ac.ir/article-1-10540-en.html.

20. Markey KA, Mollan SP, Jensen RH, Sinclair AJ. Understanding idiopathic intracranial hypertension: mechanisms, management, and future directions. Lancet Neurol 2016; 15(1): 78-91. http://doi.org/10.1016/S1474-4422(15)00298-7.

21. Thurtell MJ. Idiopathic Intracranial Hypertension. Continuum (Minneap $\begin{array}{lll}\text { Minn) 2019; 25(5): } & \text { 1289-1309. }\end{array}$ http://doi.org/10.1212/CON.0000000000000770.

22. Yuh WTC, Zhu M, Taoka T, Quets JP, Maley JE, Muhonen MG, et al. MR imaging of pituitary morphology in idiopathic intracranial hypertension. J Magnc Reson Imaging 2000; 12(6): 808-813. http://doi.org/10.1002/1522-2586(200012)12:6<808::aidjmri3>3.0.co;2-n

23. Fouad W. Review of empty sella syndrome and its surgical management. Alexandria Journal of Medicine 2011; 47(2): 139-147. http://doi.org/10.1016/j.ajme.2011.06.005.

24. Fama' F, Vita R, Sindoni A, Vinci SL, Giorgianni G, Grasso L, et al. High frequency of empty sella, with gender differences, in the early neuroradiology evaluation of patients with traumatic brain injury. A prospective study. J Clin Transl Endocrinol 2019; 15: 54-61. http://doi.org/10.1016/j.jcte.2018.12.008.

25. Gharib H, Frey HM, Laws ER Jr, Randall RV, Scheithauer BW. Coexistent primary empty sella syndrome and hyperprolactinemia. Report of 11 cases. Arch Intern Med 1983; 143(7): 1383-1386. https://pubmed.ncbi.nlm.nih.gov/6870411.

26. Thwin M, Brophy BP. Hyperprolactinaemia and the empty sella. J Clin Neurosci 2012; 19(4): 605-606. http://doi.org/10.1016/j.jocn.2011.06.025.

27. Taieb A, Maha KN, El Abed YH, Beizig AM, Chadli MC, Ach K. Macroprolactinemia and Empty Sella Syndrome. Pan Afr Med J 2017; 27: 278. http://doi.org/10.11604/pamj.2017.27.278.11361.

28. Dr. Blevins reviews an empty sella case. 2018 https://www.pituitaryworldnews.org/dr-blevins-reviews-empty-sellacase.

29. Nad' YuG. Hypoprolactinemia and empty sella turcica syndrome: diagnostic and clinical features. International science project 2017; (1): 25-27. Russian.

30. Ghatnatti V, Sarma D, Saikia U. Empty sella syndrome - beyond being an incidental finding. Indian J Endocrinol Metab 2012; 16(2): S321S323. http://doi.org/10.4103/2230-8210.104075.

31. Dedov II, Fofanova OV, Vorontsov AV, Vladimirova VP, Peterkova VA. The triad of adenohypophyseal and pituitary pedicle hypoplasia and neurohypophyseal ectopy. MR tomographic diagnosis. Problems of Endocrinology 2001; 47(5): 13-17. Russian. https://doi.org/10.14341/probl11604.

32. Liu W, Zhou H, Neidert MC, Schmid C, Bernays R-L, Ni M, et al. Growth hormone secreting pituitary microadenomas and empty sella - An under-recognized association? Clin Neurol Neurosurg 2014; 126: 1823. http://doi.org/10.1016/j.clineuro.2014.08.012.

33. Lubrano C, Tenuta M, Costantini D, Specchia P, Barbaro G, Basciani S, et al. Severe growth hormone deficiency and empty sella in obesity: a cross-sectional study. Endocrine 2015; 49(2): 503-511. http://doi.org/10.1007/s12020-015-0530-0.

34. Rani PR, Maheshwari R, Reddy TS, Prasad NR, Reddy PA. Study of prevalence of endocrine abnormalities in primary empty sella. Indian $\mathrm{J}$ Endocrinol Metab 2013; 17(7): 125-126. http://doi.org/10.4103/22308210.119527.

35. Cannavò $S$, Curtò L, Venturino $M$, Squadrito S, Almoto $B$, Narbone MC, et al. Abnormalities of hypothalamic-pituitary-thyroid axis in patients with primary empty sella. J Endocrinol Invest 2000; 25(3): 236-239. https://doi.org/10.1007/BF03343996.

36. Guitelman M, Garcia Basavilbaso N, Vitale M, Chervin A, Katz D, Miragaya K, et al. Primary empty sella (PES): a review of 175 cases. Pituitary 2013; 16(2): 270-274. http://doi.org/10.1007/s11102-0120416-6.

37. Zuhur SS, Kuzu I, Ozturk FY, Uysal E, Altuntas Y. Anterior Pituitary Hormone Deficiency in Subjects with Total and Partial Primary Empty Sella: Do All Cases Need Endocrinological Evaluation? Turk Neurosurg 
2014; 24(3): 374-379. https://doi.org/10.5137/1019-5149.JTN.867113.0.

38. Manavela MP, Goodall CM, Katz SB, Moncet D, Bruno OD. The association of Cushing's desease and primary empty sella turcica.
Pituitary
2001;
$4(3)$
145-151. http://doi.org/10.1023/a:1015310806063.

39. Lupi I, Manetti L, Raffaelli V, Grasso L, Sardella C, Cosonitti M, et al. Pituitary autoimmunity is associated with hypopituitarism in patients with primary empty sella. J Endocrinol Invest 2011; 34(8): e240-e244. https://doi.org/10.3275/7758.

40. Özkan Y, Colak R. Sheehan syndrome: clinical and laboratory evaluation of 20 cases. Neuro Endocrinol Lett 2005; 26(3): 257-260. https://pubmed.ncbi.nlm.nih.gov/15990732.

41. Braiteh N, Breiteh N, Kashou HE. Sinus Bradycardia as a Rare and Unusual Presentation of Partial Empty Sella Syndrome: A Case Report. Am I Case Rep 2019; 20: 1071-1074. http://doi.org/10.12659/AJCR.916812.

42. Sethuraman VK, Viswanathan S, Aghoram R. Refractory Hypoglycemia and Seizures as the Initial Presenting Manifestation of Empty Sella Syndrome. $\quad$ Cureus 2018; 10(6): e2803. http://doi.org/10.7759/cureus.2803.

\section{Authors:}

Victoria B. Sharavii - Medical student, International School Medicine of the Future, I.M. Sechenov First Moscow State Medical University (Sechenov University), Moscow, Russia. https://orcid.org/0000-0003-4411-3624.

Natalya A. Shnayder - MD, DSc, Professor, Leading Researcher of Center of Personalized Psychiatry and Neurology, V.M. Bekhterev National Medical Research Center for Psychiatry and Neurology, Saint-Petersburg; V.F. Voyno-Yasenetsky Krasnoyarsk State Medical University, Krasnoyarsk, Russia. https://orcid.org/0000-0002-2840-837X.

Lada K. Sharavii - MD, PhD, Department of Neurology, Public healthcare institution of Republic of Tuva Republican children's hospital, Kyzyl, Russia. https://orcid.org/0000-0002-9032-8485.

Marina M. Petrova - MD, DSc, Professor, Head of the Department of Ambulance Care, V.F. Voyno-Yasenetsky Krasnoyarsk State Medical University, Krasnoyarsk, Russia. https://orcid.org/0000-0002-8493-0058.

Regina F. Nasyrova - MD, DSc, General Researcher, Head of the Department of Personalized Psychiatry and Neurology, V.M. Bekhterev National Medical Research Center for Psychiatry and Neurology, SaintPetersburg, Russia; General Researcher of Research Laboratory OpenLab Gene and Cell Techologies of Institute of Fundamental Medicine and Biology, Kazan Federal University, Kazan, Russia. https://orcid.org/00000003-1874-9434. 